\title{
Simple storage (CO2-free) of porcine morulae for up to three days maintains the in vitro viability and developmental competence
}

C. A. Martinez, A. Nohalez, I. Parrilla, X. Lucas, J . Sanchez-Osorio, J . Roca, C. Cuello, Heriberto Rodriguez-Martinez, E. A. Martinez and M. A. Gil

The self-archived postprint version of this journal article is available at Linköping University Institutional Repository (DiVA):

http:// urn.kb.se/ resolve?urn=urn:nbn:se:liu:diva- 145440

N.B.: When citing this work, cite the original publication.

Martinez, C. A., Nohalez, A., Parrilla, I., Lucas, X., Sanchez-Osorio, J ., Roca, J ., Cuello, C., RodriguezMartinez, H., Martinez, E. A., Gil, M. A., (2018), Simple storage (CO2-free) of porcine morulae for up to three days maintains the in vitro viability and developmental competence, Theriogenology, 108, 229-238. https:// doi.org/ 10.1016/j.theriogenology.2017.12.001

Original publication available at:

https:// doi.org/ 10.1016/j.theriogenology.2017.12.001

Copyright: Elsevier

http:// www.elsevier.com/

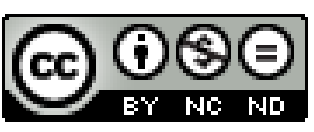


Simple storage ( $\mathrm{CO}_{2}$-free) of porcine morulae for up to three days maintains the in vitro viability and developmental competence

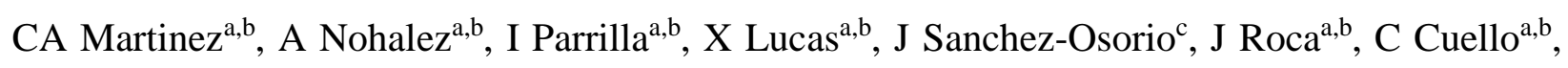
H Rodriguez-Martinez $^{\mathrm{d}}$, EA Martinez ${ }^{\mathrm{a}, \mathrm{b}^{*}}, \mathrm{MA} \mathrm{Gil}^{\mathrm{a}, \mathrm{b}}$

${ }^{a}$ Faculty of Veterinary Medicine, International Excellence Campus for Higher Education and Research “Campus Mare Nostrum”, University of Murcia, Murcia, Spain

${ }^{b}$ Institute for Biomedical Research of Murcia (IMIB-Arrixaca), Murcia, Spain

${ }^{\mathrm{c} D e p a r t m e n t ~ o f ~ G e n e t i c, ~ T o p i g s ~ N o r s v i n ~ E s p a n ̃ a, ~ M a d r i d, ~ S p a i n ~}$

${ }^{\mathrm{d}}$ Department of Clinical \& Experimental Medicine (IKE), Linköping University, Linköping, Sweden

\section{*Corresponding author}

Emilio A. Martinez

Facultad de Veterinaria. Campus de Espinardo, 30100, Murcia, Spain

E-mail: emilio@um.es

Tel.: +34 868884734

Fax: +34 868887069 


\begin{abstract}
The advancement of porcine embryo transfer (ET) technology is constrained by regulatory hurdles (liquid nitrogen transportation) or, more importantly, the technical obstacles of using vitrified embryos in combination with nonsurgical deep uterine ET technology. Maintaining embryos in culture during transport and prior ET collides with the need of $\mathrm{CO}_{2}$ gassing and the best choice of culture medium. In this work, we describe storage conditions for short-term embryo $\mathrm{CO}_{2}$-free storage that allowed for a majority of in vivo-derived porcine morulae to survive after 3 days of storage in a liquid state, and to develop to the blastocyst stage unhatched, a sanitary prerequisite for ET. The storage conditions included NCSU-23 medium supplemented with bovine serum albumin, where bicarbonate was partially replaced by HEPES to avoid the need for $\mathrm{CO}_{2}$ gassing, and a temperature of $37^{\circ} \mathrm{C}$. These conditions were able to maintain the functionality of the stored embryos (hatching capacity after exposure to conventional culture conditions) and their developmental competence after ET (normal fetuses by day 38 of pregnancy). Use of this strategy of $\mathrm{CO}_{2}$-free storage should allow the shipment of fresh embryos worldwide in the absence of liquid nitrogen.
\end{abstract}

Keywords: $\mathrm{CO}_{2}$-free embryo storage; morulae; blastocyst; embryo transfer; pig. 


\section{Introduction}

Genetic spreading by use of transfer of embryos with an intact zona pellucida (ZP) notably reduces the risk of disease transmission between the donor and recipient farms associated to commerce with live animals. Porcine embryo transfer (ET) technology has advanced dramatically over the past years, particularly through the development of a nonsurgical deep uterine (NsDU) ET technique and the refinement of procedures for embryo preservation (reviewed in [1]).

High reproductive performance of the recipients has been reported after NsDU-ET of 24 to 30 fresh ( 0 h to $6 \mathrm{~h}$ post-collection) morulae or unhatched blastocysts [2-4]. However, in commercial programs, the embryos require a longer storage period to allow for their transportation from the donor farm to the recipient farm. Because cryopreservation allows for the unlimited preservation of embryos and the shipment of embryos to locations worldwide, it should be the preferred storage method for pig embryos. Vitrification is the only procedure proven effective for the cryopreservation of porcine embryos to date. Currently, high percentages (80-95\%) of untreated morulae and blastocysts survive the in vitro vitrification and warming processes (reviewed in [1,5]). Moreover, vitrified-warmed morulae and blastocysts retain their capacity to develop in vivo as demonstrated by the high farrowing rates and litter sizes achieved when they are surgically transferred into the recipients (reviewed in [1]). However, the use of vitrified-warmed embryos has several disadvantages, such as the need to comply with strict regulations for the air handling and transport of liquid nitrogen $\left(\mathrm{N}_{2} \mathrm{~L}\right)$-dewers, the risk of devitrification when dry-shipping containers are used for air transportation or the need to have $\mathrm{N}_{2} \mathrm{~L}$ and $\mathrm{N}_{2} \mathrm{~L}$ containers on the recipient farms to warrant safe manipulation of the embryo straws during the warming process. In addition, when vitrified embryos are used in combination 
with NsDU-ET, the number of transferred embryos has to be notably increased to obtain comparable results to the surgical fertility results mentioned above [6]. These drawbacks call for alternative procedures for short-term embryo liquid storage.

In vitro culture could serve as one of these procedures; however, two primary concerns must be considered. First, the use of the NsDU-ET technique implies the transfer of embryos deep into a uterine horn. Therefore, the embryos should be in a morula or blastocyst stage immediately prior to ET. Second, for sanitary reasons, the embryos must be transferred with an intact ZP, which excludes the use of hatching and hatched blastocysts. Under conventional conditions of in vitro culture [i.e., culture medium supplemented with bovine serum albumin (BSA) or fetal calf serum (FCS) at $38.5^{\circ} \mathrm{C}$ in humidified air with 5\% CO2], more than $20 \%$ [3] and 50\% [7] of the in vivo collected morulae and blastocysts hatched at $24 \mathrm{~h}$ of culture, respectively, which makes this process unsuitable for practical purposes. To improve this strategy, the embryos could be collected earlier when they are at the one-, two- or four-cell stages. These embryos yield high unhatched blastocyst formation rates after 3 to 5 days of conventional culture $[8,9]$ and are able to develop to term after surgical transfer into recipients $[10,11]$. However, the quality in terms of the total cell number and the in vivo developmental capacity of the resultant blastocysts was much lower than that of uncultured blastocysts [12], which suggested that the conventional conditions generally used for in vitro embryo culture were suboptimal as was subsequently proven in other studies [9,13-15]. To minimize the detrimental effects of the in vitro environment on embryonic development, we previously examined a culture period as short as $24 \mathrm{~h}$ using in vivo-derived morulae [3]. In that study, we evaluated different incubation temperatures and storage media and demonstrated that more than $95 \%$ of the porcine morulae progressed to the unhatched blastocyst stage after $24 \mathrm{~h}$ of liquid storage in a defined 
medium that did not require $\mathrm{CO}_{2}$. Furthermore, despite the embryonic developmental delay observed at the end of storage, these blastocysts yielded high fertility and prolificacy rates after NsDU-ET into recipients. Although a 24-h storage period could permit the transportation of embryos in liquid state from the origin to the recipient farm within certain distances, a longer storage period would allow for the transport of the embryos over longer distances and, therefore, a more rational use of this type of embryo.

Overall, the objective of this study was to evaluate the in vitro viability and the in vivo developmental capacity (up to 38 days post ET) when in vivo-derived pig morulae were kept for up to $72 \mathrm{~h}$ in $\mathrm{CO}_{2}$-free liquid state, comparing adequate different culture media and temperature ranges.

\section{Materials and methods}

Unless otherwise specified, reagents were obtained from Sigma-Aldrich Quimica SA (Madrid, Spain). All animal procedures complied with the European Directive 2010/63/EU for animal experiments and were a priori examined and approved by the Ethical Committee for Experimentation with Animals of the Murcia University (research code: 183/2015).

\subsection{Animals}

The embryo donors were multiparous (2 to 7 parity) Landrace $\times$ Large-White sows with similar lactation periods (21 to 24 d). After weaning, the animals were housed in individual crates in a barn with mechanical ventilation. Semen was obtained from boars (2 to 3 years of age) of proven fertility. The boars were allocated in individual pens in a climate-controlled facility (20 to $\left.25^{\circ} \mathrm{C}\right)$. 
All animals had ad libitum access to water and were fed commercial diets according to their nutrient requirements.

\subsection{Estrus detection and artificial insemination}

Embryos were obtained from sows with natural post-weaning estrus. The detection of estrus started the same day of weaning and was performed by skilled operators. Backpressure was applied on the females, and snout-to-snout contact of females with a mature boar was allowed. Sows were considered in estrus when they exhibited a clear standing reflex. Only sows starting estrus at day 4 or 5 after weaning were selected as embryo donors. The sows were inseminated at 0 and $24 \mathrm{~h}$ after the onset of estrus using the post-cervical artificial insemination procedure. Sperm doses containing $1.5 \times 10^{9}$ spermatozoa in $50 \mathrm{~mL}$ of BTS (Beltsville thawing solution; [16]) extender were produced from complete ejaculates and kept at $17^{\circ} \mathrm{C}$ for a maximum of $24 \mathrm{~h}$.

\subsection{Embryo recovery and evaluation}

Donors were subjected to laparotomy in a simple operating room located next to the experimental building of the farm. Surgeries were performed on day 5 (to collect embryos at the morula stage) and 6 (to collect blastocysts) of the cycle (day $0=$ onset of estrus) according to the experimental design. Animals were sedated by intramuscular administration of azaperone (2 $\mathrm{mg} / \mathrm{kg}$ body weight). Subsequently, sodium thiopental (7 mg/kg body weight, intravenous) was used for the induction of general anesthesia, which was maintained with isoflurane (3 to 5\%).

The embryos were recovered as previously reported [17]. Briefly, once the number of corpora lutea on the ovaries was counted, the tip of each uterine horn was flushed with $30 \mathrm{~mL}$ of modified Tyrode's lactate (TL)-HEPES-polyvinyl alcohol (PVA) medium (TL-PVA; $[3,18]$ ). 
The developmental stage and quality of the collected embryos were assessed according to the criteria of the International Embryo Transfer Society [19]. Only compacted morulae morphologically classified as excellent or good were used in the experiments.

The recovery rate was defined as the ratio of the number of embryos and oocytes and degenerate embryos recovered to the number of corpora lutea present. The fertilization rate was defined as the ratio of the number of viable embryos to the total number of embryos and oocytes and degenerate embryos collected.

\subsection{Embryo storage and embryo culture}

Morulae were washed ten times in TL-PVA medium and immediately stored according to the experimental design at different temperatures for up to $72 \mathrm{~h}$ in Eppendorf tubes containing 1.5 $\mathrm{mL}$ of different media. Following the storage period, the embryos were conventionally cultured in four-well plates containing NCSU-23 [20] supplemented with 0.4\% BSA and 10\% FCS (500 $\mu \mathrm{L}$ per well). Cultures were performed at $38.5^{\circ} \mathrm{C}, 5 \% \mathrm{CO}_{2}$ in air and $95 \%$ humidity.

\subsection{Evaluation of viability and embryonic developmental stage}

The embryos were evaluated for viability and developmental progression by stereomicroscopy. Morulae that progressed during storage or during conventional culture to blastocysts with good or excellent morphology were considered viable. The in vitro survival rate was calculated as the proportion of the number of viable embryos divided by the total number of embryos evaluated.

The stage of development was scored as follows using previously outlined criteria [14]: 1, compacted morula (embryos with blastomeres totally compacted and an undistinguishable cell boundary; 2, early blastocyst (blastocysts with an initial visible blastocoele); 3, full blastocyst 
(blastocysts with a differentiated blastocoele, inner cell mass and trophpoblast); 4, expanded blastocyst (full blastocysts with increased outer diameter and thinned ZP); and 5, hatching/hatched blastocyst (expanded blastocyst with fractured or lost ZP). The hatching rate was defined as the proportion of the number of hatching or hatched embryos divided by the total number of embryos evaluated.

\subsection{Measurement of embryonic size}

Some embryos were photographed and their outer diameter (ZP included) and the width of the ZP were retrospectively measured using the open-source software ImageJ (National Institutes of Health; http://rsbweb.nih.gov/ij/).

\subsection{Evaluation of total cell number}

Embryos were fixed in 4\% paraformaldehyde in $0.1 \mathrm{M}$ phosphate-buffered saline (PBS) for 30 min at room temperature. The embryos were then washed twice with PBS supplemented with 3 $\mathrm{mg} / \mathrm{mL}$ BSA and mounted in $4 \mu \mathrm{L}$ of Vectashield (Vector, Burlingame, CA, USA) containing 10 $\mu \mathrm{g} / \mathrm{mL}$ Hoechst 33342. The embryos were photographed using a fluorescence microscope with an excitation filter of 330 to $380 \mathrm{~nm}$. The total cell number per blastocyst was determined by counting the number of nuclei with blue fluorescence. The cell counts were all performed by the same person using the same procedure and instruments.

\subsection{Embryo transfer}

Transfers were surgically performed in recipients on day 5 of the cycle. Before transfer, each recipient was treated with a long-acting amoxicillin suspension (Clamoxyl LA; Pfizer, Madrid, 
Spain; $15 \mathrm{mg} / \mathrm{kg}$, i.m.). The surgical procedure was similar to that described for embryo collection. The embryos were loaded into an ET catheter (Emtract Delphin, Gynétics, Lommel, Belgium) for transfer into the recipients. The transfer catheter was loaded with air bubbles that separated the $30-\mu \mathrm{L}$ drop of medium that contained the embryos from two $50-\mu \mathrm{L}$ drops of NCSU-BSA before and after the embryos. The embryos were deposited into the tip of a uterine horn at approximately $15 \mathrm{~cm}$ from the uterotubal junction. The transfer catheter was introduced into the uterus through of a small hole in the uterine wall, which was made with blunt Adson forceps. After ET, the tip of the uterine horn was reintroduced inside the abdominal cavity, the incision was sutured with continuous 1-polyglactin 910 sutures in three layers and the area was treated with chlorhexidine.

\subsection{Experimental design}

\subsubsection{Experiment 1}

This experiment was designed to evaluate the influence of storage temperature and medium on in vitro embryo survival and development of morulae stored for $48 \mathrm{~h}$. Immediately after collection, groups of 7 to 10 morulae were stored for $48 \mathrm{~h}$ at $25^{\circ} \mathrm{C}$ or $37^{\circ} \mathrm{C}$ in TL-PVA medium (defined medium) or in NCSU-23 medium [20] supplemented with $10 \mathrm{mM}$ HEPES and $0.4 \%$ of BSA (semi-defined medium; NCSU-BSA). Non-stored morulae cultured under conventional conditions (i.e., $500 \mu \mathrm{L}$ of NCSU-23 medium supplemented with $0.4 \%$ BSA and $10 \%$ FCS at $38.5^{\circ} \mathrm{C}$ in humidified air with $5 \% \mathrm{CO}_{2}$ ) were used as controls. Embryos from each donor were equally and randomly allocated to each of the groups. At $0 \mathrm{~h}$ and $48 \mathrm{~h}$ of storage, embryos were photographed for the subsequent determination of their outer diameter and ZP thickness. At the 
end of storage, embryos were also assessed for viability and development stage, and then they were conventionally cultured for an additional $48 \mathrm{~h}$ to reassess viability and evaluate their hatching competence.

\subsubsection{Experiment 2}

Because the results of Experiment 1 showed that NCSU-BSA at $37^{\circ} \mathrm{C}$ was superior to the other conditions, we designed a second experiment with two aims: first, to evaluate the effectiveness of that medium (NCSU-23) supplemented with PVA instead of BSA; and second, to determine the viability of increasing the storage period until $72 \mathrm{~h}$. Morulae were stored at $37^{\circ} \mathrm{C}$ in NCSUBSA or NCSU-PVA for $72 \mathrm{~h}$ and then morphologically assessed for viability and development. Subsequently, the embryos were cultured for $24 \mathrm{~h}$ under conventional conditions to reassess their

viability and evaluate their hatching competence following the same criteria described for Experiment 1. Morulae not subject to storage and cultured under conventional conditions were used as controls.

\subsubsection{Experiment 3}

This experiment was conducted to determine the in vivo developmental potential of the blastocysts derived from morulae stored in NCSU-BSA medium at $37^{\circ} \mathrm{C}$ for $72 \mathrm{~h}$. At the end of storage, viable embryos that progressed to the unhatched blastocyst stage were transferred to recipients. The control group was formed by un-stored blastocysts, which were transferred to recipients within $3 \mathrm{~h}$ of recovery. A total of 25 blastocysts was transferred into each recipient. Twelve days after the transfer, recipients were evaluated daily for signs of estrus. Pregnancy was diagnosed by ultrasonography on Days 20 to 22 post-transfer. The uterus of each pregnant 
recipient was collected at slaughter by day 38 to 41 of pregnancy, and the number of fetuses in each recipient was recorded.

\subsection{Statistical analysis}

The statistical analysis was performed using the IBM SPSS 19 Statistics package (IBM, Chicago, IL, USA). Binary variables were compared using Fisher's exact test. The development stage scores were analyzed using the Kruskal-Wallis test. Because this test revealed significant differences, two by two comparisons were performed using the Mann-Whitney U-test for two independent samples. Continuous variables were analyzed for normality by the KolmogorovSmirnov test, and groups were compared by a mixed-model ANOVA. The ANOVA model included the fixed effects of temperature and medium and their interaction (Experiment 1) or the medium (Experiment 2) and the random effect of the replicate. If the ANOVA revealed a significant effect, the means were compared using Bonferroni’s test. The outer diameter and ZP thickness at $0 \mathrm{~h}$ and $48 \mathrm{~h}$ of storage within each group were compared using Student's t test for related samples, and the total cell number per blastocyst between groups was compared using Student's t test for independent samples. Differences were considered significant at $\mathrm{P}<0.05$. The results are expressed as percentages and mean \pm S.E.M.

\section{Results}

\subsection{Experiment 1}

Out of 20 sows, sixteen (80\%) had morulae, three (15.0\%) had blastocysts and one (5.0\%) had only oocytes. The mean ovulation rate per pregnant sow was $22.1 \pm 1.7$ corpora lutea (range 15 to 
28 corpora lutea). The recovery and fertilization rates were $94.0 \%$ and $92.4 \%$, respectively. A total of 316 morulae were used in this experiment. The embryos recovered at the blastocyst stage were used for other research purposes.

The embryonic viability at $48 \mathrm{~h}$ of storage under different temperatures and media conditions is shown in Figure 1. At the end of the storage period, the TL-PVA medium at $25^{\circ} \mathrm{C}$ was harmful $(\mathrm{P}<0.05)$ for embryonic viability $(73.9 \%)$ compared with the control $(93.2 \%)$ or the other experimental groups (range: 90.9\% to 98.3\%). Following conventional culture conditions, the NCSU-BSA medium group at $37^{\circ} \mathrm{C}$ was the only group with embryonic viability rates similar (96.7\%) to that of the control group (93.2\%).

Embryonic development at $48 \mathrm{~h}$ of storage was delayed $(\mathrm{P}<0.01)$ in all experimental groups compared with the controls, with the delay was more pronounced at $25^{\circ} \mathrm{C}$ than at $37^{\circ} \mathrm{C}$ (Figure 2A) regardless of the storage medium. The developmental delay continued at $24 \mathrm{~h}$ and 48 $\mathrm{h}$ of conventional culture in all experimental groups except for embryos stored at $37^{\circ} \mathrm{C}$ in NCSUBSA, which achieved similar development as the control embryos during conventional culture (Figure 2B-D).

Consistent with these data, a comparable pattern was observed for the outer diameters and the thicknesses of the ZP of the embryos at the end of storage period (Table 1). Significant interactions were not observed between temperature and medium. In addition, differences in the diameter and ZP thickness were not observed between $0 \mathrm{~h}$ and $48 \mathrm{~h}$ of storage for embryos stored at $25^{\circ} \mathrm{C}$. In contrast, embryos stored at $37^{\circ} \mathrm{C}$, like the control embryos, had a larger diameter $(\mathrm{P}<0.001)$ and a smaller $\mathrm{ZP}$ thickness $(\mathrm{P}<0.001)$ at $48 \mathrm{~h}$ than at $0 \mathrm{~h}$ of storage.

Although most embryos stored at $37^{\circ} \mathrm{C}$ reached the blastocyst stage, none of them, unlike controls, hatched at the end of storage (Figure 2E-G). The embryos stored at $37^{\circ} \mathrm{C}$ in NCSU-BSA 
had the same hatching ability as the control embryos at the end of the conventional culture ( 85\%), and these values were much higher $(\mathrm{P}<0.01)$ than those observed in the other experimental groups $(<25 \%)$ (Figure 2G). Despite similarities observed by the end of the conventional culture between embryos stored at $37^{\circ} \mathrm{C}$ in NCSU-BSA and controls, differences were observed $(\mathrm{P}<0.001)$ in the total cell numbers between blastocysts that hatched in each group (96.6 \pm 3.1 and $149.6 \pm 12.9$ cells, respectively).

\subsection{Experiment 2}

A total of 14 donor sows was used in this experiment. Embryos at the morula and blastocyst stages were collected from 11 (78.6\%) and 3 (21.4\%) sows, respectively.

The mean number of corpora lutea in the donor sows was $18.5 \pm 1.4$ (range 12 to 29 corpora lutea). The ratio of collected embryos to the total number of corpora lutea counted was $84.9 \%$, and the fertilization rate was $95.6 \%$. Only embryos at the morula stage $(n=167)$ were used in this experiment. The embryos collected at the blastocyst stage were used for other studies.

In vitro survival of the morulae stored for up to $72 \mathrm{~h}$ is shown in Figure 3. The viability of embryos stored for $48 \mathrm{~h}$ in NCSU-BSA was not different from that observed in the control group (98.3\% and 98.0\%, respectively), but it was higher $(\mathrm{P}<0.02)$ than that of the embryos stored in NCSU-PVA medium (84.5\%). This pattern continued at $72 \mathrm{~h}$ of storage, with the differences in viability between the NCSU-PVA group (53.4\%) and the other two groups (98.3\% and $90.0 \%$ for the NCSU-BSA and control groups, respectively) becoming more pronounced $(\mathrm{P}<0.001)$. In the NCSU-PVA group, the percentage of viable embryos decreased after $24 \mathrm{~h}$ of 
conventional culture (43.1\%), whereas all viable embryos from the NCSU-BSA group remained viable after $24 \mathrm{~h}$ of conventional culture (Figure 3), which was similar to the control.

A developmental delay was observed in the stored embryos compared with the controls $(\mathrm{P}<0.02)$, and it was more evident for the embryos stored in NCSU-PVA medium (Figure 4A). This developmental delay continued in the embryos stored in NCSU-PVA medium after 24 h of conventional culture $(\mathrm{P}<0.003)$ but disappeared in the embryos from the NCSU-BSA group (Figure 4B-D). Despite the developmental delay, some embryos (6.7\%) stored in NCSU-BSA medium hatched at the end of storage (Figure 4E-G). Although the hatching ability after conventional culture was similar for the embryos from NCSU-BSA and control groups (86.0\% and $76.4 \%$, respectively), a significant reduction in the total cell number per hatched blastocyst was observed (85.5 \pm 4.8 and $143.6 \pm 6.6$ cells, respectively). In contrast, none of the embryos stored in the NCSU-PVA medium hatched at the end of storage or after $24 \mathrm{~h}$ of conventional culture.

Representative images showing the development of morulae stored in NCSU-BSA medium at $37^{\circ} \mathrm{C}$ for $72 \mathrm{~h}$ are depicted in Figure 5.

\subsection{Experiment 3}

For the transfers, we used 86 morulae collected from five donors at day 5, which were stored for 72 days in NCSU-BSA, and 75 blastocysts recovered from five donors at day 6, which were transferred just after collection (control group). Blastocysts derived from stored morulae and control blastocysts were transferred to a total of six recipients (three per group). One pregnant recipient from the NCSU-BSA group returned to estrus on day 28. The remaining recipients were pregnant and maintained the pregnancy until slaughter. The mean number of fetuses 
collected in the recipients in the NCSU-BSA group was $11.0 \pm 4.0$, of which $10.0 \pm 3.0$ fetuses were diagnoses as alive. The recipients transferred with control embryos had $15.3 \pm 0.9$ fetuses, of which $12.7 \pm 1.3$ were alive. These results indicate that in pregnant recipients, $40.0 \%$ of the stored embryos were able to develop until day 38 of pregnancy and form live fetuses, whereas the percentage was $50.8 \%$ in the control embryos.

\section{Discussion}

The legal regulatory challenges associated with the transportation of $\mathrm{N}_{2} \mathrm{~L}$ and, more importantly, the remaining technical obstacles to the use of cryopreserved embryos in combination with NsDU-ET [6] have encouraged the development of alternative methods for short-term embryo storage in a liquid state $[3,21]$. In the present study, we chose a particular stage of embryo development and two culture media for the storage of porcine embryos in a liquid state. We selected embryos at the morula stage for several reasons: first, to avoid the adverse effects of long culture periods of earlier stage embryos on the quality of the resulting blastocysts; second, because under conventional culture conditions, most morulae should have an autonomy of at least $24 \mathrm{~h}$ without progression to the hatching blastocyst stage; third, because high in vitro embryo viability (>95\%) of porcine morulae stored for $24 \mathrm{~h}$ at $37^{\circ} \mathrm{C}$ in a chemically defined medium was obtained in a previous study. Moreover, despite the storage conditions tested produced a developmental delay, the resulting blastocysts kept their capacity to develop to term following NsDU-ET at similar levels to that of the control blastocysts [3]; and fourth, because although fresh morulae together with NsDU-ET have provided optimal reproductive results, the use of blastocysts is more advisable for ET programs because these embryos tolerate a wider 
donor-recipient asynchrony [22]. Therefore, blastocysts derived from stored morulae ought to have a great potential for commercial ET.

From a practical perspective and to bypass additional liquid-state embryo shipment requirements, it is more convenient to use storage media capable of maintaining proper $\mathrm{pH}$ levels without the need for $\mathrm{CO}_{2}$ gas; therefore, we used two media supplemented with HEPES: TLPVA medium, which is a chemically defined medium frequently used for porcine embryo recovery and handling $[4,22,23]$, and an adaptation of the extensively used porcine embryo culture NCSU-23 medium [20] supplemented with BSA, in which bicarbonate was partially replaced by HEPES (NCSU-BSA). In addition, we decided to prolong the storage period from the $24 \mathrm{~h}$ used in our previous study [3] to $72 \mathrm{~h}$ because a longer period should allow for the global distribution of embryos and their efficient utilization in a liquid state.

In Experiment 1, the embryo survival rate at the end of $48 \mathrm{~h}$ of storage was not different between the controls and the experimental groups with the exception of the TL-PVA- $25^{\circ} \mathrm{C}$ group, which showed the lowest survival. However, when viable embryos following storage were conventionally cultured for $24 \mathrm{~h}$ to $48 \mathrm{~h}$ to reassess their viability, only the embryos from the NCSU-BSA group stored at $37^{\circ} \mathrm{C}$ maintained the same survival rate as the controls. These results demonstrated that a temperature of $25^{\circ} \mathrm{C}$ during $48 \mathrm{~h}$ of storage was harmful for embryonic viability regardless of the storage medium used. In our previous study [3] and in a study by Pomar et al. [21], high embryonic survival rates were achieved after $24 \mathrm{~h}$ of storage at $25^{\circ} \mathrm{C}$ using media supplemented with BSA. However, in both cases, the embryos were not further cultured to reassess viability; therefore, the results do not indicate the effects of storage on embryo functionality. In the present study, we also obtained high survival rates for embryos stored at $25^{\circ} \mathrm{C}$ in a BSA medium ( $\left.\sim 95 \%\right)$. However, almost $20 \%$ of these embryos degenerated 
between 24 and $48 \mathrm{~h}$ of conventional culture. This finding suggests that some embryos with apparently normal morphology were functionally damaged during storage.

Storage medium played an important role when the preservation temperature was $37^{\circ} \mathrm{C}$, with the NCSU-BSA medium showing much more effective results than the TL-PVA medium. We previously demonstrated that TL-PVA provides a chemically defined medium capable of maintaining high in vitro and in vivo viability of porcine morulae stored at $37^{\circ} \mathrm{C}$ for $24 \mathrm{~h}$. However, it becomes clear from our present results that the TL-PVA medium at $37^{\circ} \mathrm{C}$ was not efficient to support a $48 \mathrm{~h}$ storage period. Although these conditions supported embryo viability up to $48 \mathrm{~h}$ of storage (>90\% survival rate), a considerable proportion of embryos from the TLPVA medium group that were classified as viable at the end of storage period was not able to further progress and degenerated under conventional culture conditions. This finding suggests that embryo injuries occurred during preservation in TL-PVA medium at $37^{\circ} \mathrm{C}$, which is similar to the results for storage at $25^{\circ} \mathrm{C}$. In contrast, our present results also indicate that it is feasible to achieve high survival rates after $48 \mathrm{~h}$ of storage at $37^{\circ} \mathrm{C}$ in a medium containing BSA with successive embryo development similar to that of the control embryos. To avoid any risk of viral contamination, it would be preferable to use of media without serum or serum components [24,25]. Nevertheless, BSA clearly possesses fewer hazards than serum for disease transmission via ET [25] and is infinitely less dangerous than the exchange of live animals between farms. As proof, BSA is currently incorporated in many commercial media used in bovine ET, a booming worldwide technology.

Our present results also indicate a significant embryonic developmental delay at $48 \mathrm{~h}$ of storage in all experimental groups compared with the controls, with the delay more severe at $25^{\circ} \mathrm{C}$ than at $37^{\circ} \mathrm{C}$ regardless the storage medium. These results are consistent with those 
reported for porcine morulae stored for $24 \mathrm{~h}$ under similar conditions [3] and for stored embryos in other species $[26,27]$. The differences in embryo development were in accordance with the size of the embryos, which confirms the results of previous studies [3,21].

Interestingly, the viable embryos from all experimental groups were able to further progress after storage when they were incubated under conventional culture conditions. However, only those embryos stored at $37^{\circ} \mathrm{C}$ in NCSU-BSA medium achieved a similar degree of development as the control embryos at the end of conventional culture, although having 1.5fold lower total cell number. This finding indicates an important mitotic reduction that could be related to dysregulations of the genome or embryonic metabolism during storage, which has been previously reported for embryos of other species under hypothermic conditions [27,28]. Nevertheless, the fact that the embryos stored at $37^{\circ} \mathrm{C}$ in NCSU-BSA medium had a similar hatching rate at the end of the conventional culture as the control embryos predicts their correct functionality because the hatching rate has been shown to represent a sensitive biological indicator of blastocyst quality and developmental potential [29].

The present study showed that approximately $30 \%$ and $80 \%$ of the control morulae hatched at $48 \mathrm{~h}$ and $72 \mathrm{~h}$ of conventional culture, respectively. In contrast, none of the stored embryos hatched at $48 \mathrm{~h}$ of storage, regardless of the temperature and medium used. This finding is highly relevant from a sanitary standpoint, since the ZP must remain intact until the embryos are transferred to recipients to preserve appropriate sanitary conditions [30].

In our second experiment, we evaluated the reliability of NCSU-23 medium supplemented with PVS instead of BSA in an attempt to develop a storage method lacking animal components. In addition, we extended the storage period to $72 \mathrm{~h}$ to provide sufficient time for the efficient international exchange of liquid-kept embryos. The results from this 
experiment clearly indicated that the survival rates of embryos stored in NCSU-PVA medium were reduced at $48 \mathrm{~h}$ and $72 \mathrm{~h}$ of storage compared with those obtained in the NCSU-BSA and control groups. Moreover, approximately $40 \%$ of embryos stored in the absence of BSA survived after $24 \mathrm{~h}$ of conventional culture, which means that the final viability in that group was decreased more than 2 fold in relation to that of the other groups. In contrast, the viability of embryos stored in the presence of BSA was similar to that of the control embryos at each evaluated time-point. In addition to viability, two other fundamental differences between both media were noted. First, the developmental delay observed in embryos stored for $72 \mathrm{~h}$ in NCSUBSA medium compared with the controls vanished after $24 \mathrm{~h}$ of conventional culture, whereas this was not observed in the embryos maintained in NCSU-PVA medium. Second, the hatching capacity of embryos in the presence of BSA was similar to that of the controls but was totally inhibited in the absence of BSA, even after conventional culture. Taken together, these results indicate a protective effect of BSA on the embryos under the storage conditions used in our study. This observation is not surprising considering the numerous benefits BSA provides to the in vitro embryo culture (reviewed in [31]), including its antioxidant, nutritive and $\mathrm{pH}$ buffer roles during embryonic development. Additionally, other studies have also reported the benefits of BSA prolonging viability of sperm stored above the freezing point [32] and protecting sperm DNA [33] and membrane integrity [34]. However, we must note that a proportion of the stored morulae, although small, hatched at $72 \mathrm{~h}$ of storage in the NCSU-BSA medium, and these embryos should therefore be discharged for sanitary reasons in commercial ET programs.

Our results firmly suggest that despite keeping embryos in NCSU-BSA medium at $37^{\circ} \mathrm{C}$ delayed their development after $72 \mathrm{~h}$ of storage, a proportion of the stored embryos were competent for further develop in vivo, at least, until day 38 of pregnancy. This fact was not 
surprising because we previously reported that in vivo embryo development was not affected after the transfer of developmentally delayed pig embryos stored for $24 \mathrm{~h}$ [3]. Similar findings have also been reported in mouse embryos [27]. However, because of the limited number of recipients used in our study, we did not compare the in vivo developmental potential of the stored embryos to that of the un-stored control blastocysts, and we can state only that a proportion of the stored embryos under the conditions used in our study were developmentally competent.

\subsection{Conclusions}

In conclusion, morulae stored at $37^{\circ} \mathrm{C}$ in a semi-defined medium containing BSA maintained their in vitro viability and developmental competence for up to $72 \mathrm{~h}$. Furthermore, none of the blastocysts derived from morulae stored under these conditions hatched at $48 \mathrm{~h}$ of storage, and only a small proportion of them hatched at $72 \mathrm{~h}$. Additionally, these embryos were able to develop into normal fetuses by day 38 of pregnancy. Although these findings open new possibilities for porcine embryo preservation in liquid state, further research is needed to determine the capacity of these embryos to undergo full-term development following NsDU-ET.

\section{Acknowledgments}

The authors are grateful to Moises Gonzalvez and Borja Tarraga for their assistance throughout this work. We thank the Ministry of Economy and Competitiveness (Madrid, Spain) for its grantbased support to CA Martinez and A Nohalez (BES-2013-064087 and BES-2013-064069, respectively). 


\section{Funding}

This study was supported by the Ministry of Economy and Competitiveness (Madrid, Spain)/the European Regional Development Fund (grant numbers RTC-2016-5448-2 and AGL2015-69735R); and the Seneca Foundation, Murcia, Spain (grant number 19892/GERM/15).

\section{Role of the funding source}

Funding sources did not have any involvement in the study design, in the collection, analysis and interpretation of data, in the writing of the report, and in the decision to submit the article for publication.

\section{Author contributions}

CA Martinez, C Cuello, H Rodriguez-Martinez, EA Martinez and MA Gil conceived, designed and directed the study. CA Martinez, A Nohalez, I Parrilla, X Lucas, J Sanchez-Osorio, C Cuello, EA Martinez and MA Gil performed the experiments. CA Martinez, C Cuello, H Rodriguez-Martinez, EA Martinez and MA Gil analyzed and interpreted the data. CA Martinez wrote the manuscript. J Roca, C Cuello, H Rodriguez-Martinez, EA Martinez and MA Gil. revised the manuscript. All authors approved the manuscript for publication. EA Martinez, MA Gil, J Roca and J Sanchez-Osorio obtained the funding to carry out the study.

\section{Declaration of interest}

None of the authors have any conflicts of interest to declare. 


\section{References}

[1] Martinez EA, Cuello C, Parrilla I, Martinez CA, Nohalez A, Vazquez JL, et al. Recent advances toward the practical application of embryo transfer in pigs. Theriogenology 2016; 85:152-61.

[2] Martinez EA, Caamano JN, Gil MA, Rieke A, McCauley TC, Cantley TC, et al. Successful nonsurgical deep uterine embryo transfer in pigs. Theriogenology 2004; 61:137-46.

[3] Martinez EA, Angel MA, Cuello C, Sanchez-Osorio J, Gomis J, Parrilla I, et al. Successful non-surgical deep uterine transfer of porcine morulae after 24 hour culture in a chemically defined medium. PLoS One 2014; 9:e104696.

[4] Angel MA, Gil MA, Cuello C, Sanchez-Osorio J, Gomis J, Parrilla I, et al. The effects of superovulation of donor sows on ovarian response and embryo development after nonsurgical deep-uterine embryo transfer. Theriogenology 2014; 81:832-9.

[5] Martinez EA, Gil MA, Cuello C, Sanchez-Osorio J, Gomis J, Parrilla I, et al.. Current progress in non-surgical embryo transfer with fresh and vitrified/warmed pig embryos. In: Rodriguez-Martinez H, Soede NM, Flowers WN, editors. Control of Pig Reproduction IX, Leicestershire, UK: Context Products Ltd; 2013. p. 101-12.

[6] Martinez EA, Martinez CA, Nohalez A, Sanchez-Osorio J, Vazquez JM, Roca J, et al. Nonsurgical deep uterine transfer of vitrified, in vivo-derived, porcine embryos is as effective as the default surgical approach. Sci Rep 2015; 5:10587.

[7] Cuello C, Sanchez-Osorio J, Alminana C, Gil MA, Parrilla I, Roca J, et al. Superfine open pulled straws vitrification of porcine blastocysts does not require pretreatment with cytochalasin B and/or centrifugation. Reprod Fertil Dev 2010; 22:808-17. 
[8] Cuello C, Gil MA, Alminana C, Sanchez-Osorio J, Parrilla I, Caballero I, et al. Vitrification of in vitro cultured porcine two-to-four cell embryos. Theriogenology 2007; 68:258-64.

[9] Almiñana C, Gil MA, Cuello C, Parrilla I, Caballero I, Sanchez-Osorio J, et al. Capability of frozen-thawed boar spermatozoa to sustain pre-implantational embryo development. Anim Reprod Sci 2010; 121:145-51.

[10] James JE, Reeser PD, Davis DL, Straiton EC, Talbot AC, Polge C. Culture and longdistance shipment of swine embryos. Theriogenology 1980; 14:463-9.

[11] Niemann H, Wust A, Gardon JC. Successful intercontinental transport of porcine embryos from Europe to South America. Theriogenology 1989; 31:525-30.

[12] Blum-Reckow B, Holtz W. Transfer of porcine embryos after 3 days of in vitro culture. J Anim Sci 1991; 69:3335-42.

[13] Thompson JG. Comparison between in vivo-derived and in vitro-produced pre-elongation embryos from domestic ruminants. Reprod Fertil Dev 1997; 9:341-54.

[14] Machaty Z, Day BN, Prather RS. Development of early porcine embryos in vitro and in vivo. Biol Reprod 1998; 59:451-5.

[15] Rizos D, Ward F, Duffy P, Boland MP, Lonergan P. Consequences of bovine oocyte maturation, fertilization or early embryo development in vitro versus in vivo: implications for blastocyst yield and blastocyst quality. Mol Reprod Dev 2002; 61:234-48.

[16] Pursel VG, Johnson LA. Freezing of boar spermatozoa: fertilizing capacity with concentrated semen and a new thawing procedure. J Anim Sci 1975; 40:99-102. 
[17] Martinez CA, Nohalez A, Parrilla I, Vazquez JL, Roca J, Cuello C, et al. Surgical embryo collection but not nonsurgical embryo transfer compromises postintervention prolificacy in sows. Theriogenology 2017; 87:316-20.

[18] Funahashi H, Ekwall H, Rodriguez-Martinez H. Zona reaction in porcine oocytes fertilized in vivo and in vitro as seen with scanning electron microscopy. Biol Reprod 2000; 63:1437-42.

[19] Wright JM. Photographic illustrations of embryo developmental stage and quality codes. In: Stringfellow DA, Siedel SM, editors. Manual of the International Embryo Transfer Society. Savoy: IETS; 1998. p. 167-70.

[20] Petters RM, Wells KD. Culture of pig embryos. J Reprod Fertil Suppl 1993; 48:61-73.

[21] Pomar FJ, Ducro-Steverink DW, Hazeleger W, Teerds KJ, Colenbrander B, Bevers MM. Development, DNA fragmentation and cell death in porcine embryos after $24 \mathrm{~h}$ storage under different conditions. Theriogenology 2004; 61:147-58.

[22] Angel MA, Gil MA, Cuello C, Sanchez-Osorio J, Gomis J, Parrilla I, et al. An earlier uterine environment favors the in vivo development of fresh pig morulae and blastocysts transferred by a nonsurgical deep-uterine method. J Reprod Dev 2014; 60:371-6.

[23] Gomis J, Cuello C, Sanchez-Osorio J, Gil MA, Parrilla I, Angel MA, et al. Non-surgical deep intrauterine transfer of superfine open pulled straw (SOPS)-vitrified porcine embryos: evaluation of critical steps of the procedure. Theriogenology 2012; 78:1339-49.

[24] Guerin B, Nibart M, Le Guienne BM, Humblot P. Sanitary risks related to embryo transfer in domestic species. Theriogenology 1997; 47:33-42.

[25] Hasler JF. Synthetic media for culture, freezing and vitrification of bovine embryos. Reprod Fertil Dev 2010; 22:119-25. 
[26] Clark KE, Squires EL, McKinnon AO, Seidel GE, Jr. Viability of stored equine embryos. J Anim Sci 1987; 65:534-42.

[27] de Dios Hourcade J, Perez-Crespo M, Serrano A, Gutierrez-Adan A, Pintado B. In vitro and in vivo development of mice morulae after storage in non-frozen conditions. Reprod Biol Endocrinol 2012; 10:62.

[28] Sakurai T, Kimura M, Sato M. Temporary developmental arrest after storage of fertilized mouse oocytes at $4^{\circ} \mathrm{C}$ : effects on embryonic development, maternal mRNA processing and cell cycle. Mol Hum Reprod 2005; 11:325-33.

[29] Cuello C, Berthelot F, Delaleu B, Venturi E, Pastor LM, Vazquez JM, et al. The effectiveness of the stereomicroscopic evaluation of embryo quality in vitrified-warmed porcine blastocysts: an ultrastructural and cell death study. Theriogenology 2007; 67:970-82.

[30] Stringfellow DA. Recommendations for the sanitary handling of in vivo derived embryos. In: Stringfellow DA, Seidel SM, editors. Manual of the International Embryo Transfer Society. Savoy: IETS; 1998. p. 79-84.

[31] Thompson JG. In vitro culture and embryo metabolism of cattle and sheep embryos - a decade of achievement. Anim Reprod Sci 2000; 60-61:263-75.

[32] Nang CF, Osman K, Budin SB, Ismail MI, Jaffar FH, Mohamad SF, et al. Bovine serum albumin: survival and osmolarity effect in bovine spermatozoa stored above freezing point. Andrologia 2012; 44:447-53.

[33] Van Thuan N, Wakayama S, Kishigami S, Wakayama T. New preservation method for mouse spermatozoa without freezing. Biol Reprod 2005; 72:444-50. 
[34] Uysal O, Korkmaz T, Tosun H. Effect of bovine serum albumin on freezing of canine semen. Indian Vet J 2005; 82:97-8. 


\section{Figure legends}

Fig. 1. Survival rates of in vivo-produced porcine morulae after storage for $48 \mathrm{~h}$ at different temperatures and media.

Morulae were stored in TL-PVA and NCSU-BSA (both media supplemented with $10 \mathrm{mM}$ HEPES) at $25^{\circ} \mathrm{C}$ and $37^{\circ} \mathrm{C}$ for $48 \mathrm{~h}$ (dark grey bars). After storage, the viable stored embryos from each group were cultured for an additional 24-48 h under conventional culture conditions (NCSU-23 culture medium supplemented with $0.4 \%$ BSA and $10 \%$ FCS, at $38.5^{\circ} \mathrm{C}$ in humidified air with 5\% CO2) to reassess their in vitro survival (light grey bars). Control morulae were cultured under conventional conditions (NCSU-23 culture medium supplemented with $0.4 \%$ BSA and $10 \% \mathrm{FCS}$, at $38.5^{\circ} \mathrm{C}$ in humidified air with $5 \% \mathrm{CO}_{2}$ ) for $48 \mathrm{~h}$ (black bar). Viable control morulae were then conventionally cultured in fresh culture medium for an additional 2448 h (white bar). n=total number of embryos analyzed. Bars with different small letters (a, b) are significantly different $(\mathrm{P}<0.05)$. Bars with different capital letters $(\mathrm{A}, \mathrm{B})$ are significantly different $(\mathrm{P}<0.05)$.

Fig. 2. Embryonic developmental stages of in vivo-produced porcine morulae stored for $48 \mathrm{~h}$ in a liquid state.

(A) Summary of the developmental stages of morulae at the end of the storage period. Morulae were stored for $48 \mathrm{~h}$ in closed tubes containing TL-PVA or NCSU-BSA media at $25^{\circ} \mathrm{C}$ or $37^{\circ} \mathrm{C}$. *After storage, the embryos from each group were cultured under conventional conditions (NCSU-23 medium supplemented with $0.4 \%$ BSA and $10 \%$ FCS at $38.5^{\circ} \mathrm{C}$ in humidified air with 5\% CO2) for up to $48 \mathrm{~h}$ to re-evaluate the embryonic development. ${ }^{\#}$ Controls included morulae cultured under conventional conditions for $48 \mathrm{~h}$ and then maintained in fresh conventional culture medium for an additional $24 \mathrm{~h}$ to $48 \mathrm{~h}$. The developmental stage was scored according to 
the following classes: 1 , morula; 2, early blastocyst; 3 , full blastocyst; 4 , expanded blastocyst; and 5, hatching or hatched blastocyst. ${ }^{\mathrm{a}, \mathrm{b}, \mathrm{c}}$ Different letters in the same column indicate significant differences $(\mathrm{P}<0.01)$. Values are expressed as the mean \pm SEM.

(B-D) Bar graphs showing the proportion of the different embryonic developmental stages reached in each group at $48 \mathrm{~h}$ of storage (B) and after $24 \mathrm{~h}$ (C) and $48 \mathrm{~h}$ (D) of conventional culture. Bl: blastocyst.

(E-G) Bar graphs showing the hatching-hatched blastocyst rates reached in each group from morulae stored for $48 \mathrm{~h}(\mathrm{E})$ and after $24 \mathrm{~h}(\mathrm{~F})$ and $48 \mathrm{~h}(\mathrm{G})$ of conventional culture. ${ }^{\mathrm{a}, \mathrm{b}}$ Different letters represent significant differences $(\mathrm{P}<0.001)$.

Fig. 3. Survival rates of in vivo produced porcine morulae after storage for $48 \mathrm{~h}$ and $72 \mathrm{~h}$ at $37^{\circ} \mathrm{C}$ in different storage media.

Morulae were stored in NCSU-BSA and NCSU-PVA (both media supplemented with $10 \mathrm{mM}$ HEPES) at $37^{\circ} \mathrm{C}$ for $48 \mathrm{~h}$ (hatch-marked bars) and $72 \mathrm{~h}$ (striped bars). After storage, the viable stored embryos from each group were cultured for an additional $24 \mathrm{~h}$ under conventional culture conditions (NCSU-23 culture medium supplemented with $0.4 \%$ BSA and $10 \%$ FCS at $38.5^{\circ} \mathrm{C}$ in humidified air with 5\% CO2) to reassess in vitro survival (pointed bars). Control morulae were cultured under conventional conditions (NCSU-23 culture medium supplemented with $0.4 \%$ BSA and $10 \% \mathrm{FCS}$ at $38.5^{\circ} \mathrm{C}$ in humidified air with $5 \% \mathrm{CO}_{2}$ ) for $48 \mathrm{~h}$ (black bar) and $72 \mathrm{~h}$ (grey bar). Viable control morulae were then conventionally cultured in fresh culture medium for an additional $24 \mathrm{~h}$ (white bar). $\mathrm{n}=$ total number of embryos analyzed.

Bars with asterisks indicate significant differences compared with the NCSU-BSA and control groups $(* \mathrm{P}<0.02 ; * * \mathrm{P}<0.001)$. 
Fig. 4. Embryonic developmental stages of in vivo-produced porcine morulae stored for up $72 \mathrm{~h}$ in a liquid state.

(A) Summary of the developmental stages of morulae at $48 \mathrm{~h}$ of storage and the end of the storage period (72 h). Morulae were stored for $72 \mathrm{~h}$ in closed tubes containing NCSU-BSA or NCSU-PVA media at $37^{\circ} \mathrm{C}$. *After storage, the embryos from each group were cultured under conventional conditions (NCSU-23 medium supplemented with $0.4 \%$ BSA and 10\% FCS at $38.5^{\circ} \mathrm{C}$ in humidified air with $5 \% \mathrm{CO} 2$ ) for $24 \mathrm{~h}$ to re-evaluate the embryonic development. ${ }^{\#}$ Controls included morulae cultured under conventional conditions for $72 \mathrm{~h}$ and then maintained in fresh conventional culture medium for an additional $24 \mathrm{~h}$. The developmental stage was scored according to the following classes: 1, morula; 2, early blastocyst; 3 , full blastocyst; 4 , expanded blastocyst; and 5, hatching or hatched blastocyst. ${ }^{\mathrm{a}, \mathrm{b}, \mathrm{c}}$ Different letters in the same column indicate significant differences $(\mathrm{P}<0.003)$. ${ }^{\text {d,e,f }}$ Different letters in the same column indicate significant differences $(\mathrm{P}<0.02)$. Values are expressed as the mean $\pm \mathrm{SEM}$.

(B-D) Bar graphs showing the proportion of the different embryonic developmental stages reached in each group at $48 \mathrm{~h}(\mathrm{~B})$ and $72 \mathrm{~h}(\mathrm{C})$ of storage and after $24 \mathrm{~h}$ of conventional culture (D). Bl: blastocyst.

(E-G) Bar graphs showing the hatching-hatched blastocyst rates reached in each group from morulae stored for $48 \mathrm{~h}(\mathrm{E})$ and $72 \mathrm{~h}(\mathrm{~F})$ and after $24 \mathrm{~h}$ of conventional culture (G). ${ }^{\mathrm{a} b}$ Different letters represent significant differences $(\mathrm{P}<0.001)$.

Fig. 5. Preservation of in vivo-derived morulae in NCSU-BSA medium at $37^{\circ} \mathrm{C}$ for up to 72 hours. 
(A) Representative bright field images showing freshly collected pig morulae (a) and blastocysts at different developmental stages following the conventional culture of morulae for $48 \mathrm{~h}$ (b), $72 \mathrm{~h}$ (c) and $96 \mathrm{~h} \mathrm{(d).}$

(B) Representative bright field images showing freshly collected pig morulae (a') and blastocysts at different developmental stages following the storage of morulae in NCSU-BSA medium at $37^{\circ} \mathrm{C}$ for $48 \mathrm{~h}$ (b') and $72 \mathrm{~h}$ (c'). At the end of storage, the resulting blastocysts were conventionally cultured for $24 \mathrm{~h}$ to reassess their viability and hatching competence (d').

Fig. 6. Fetuses collected after embryo transfer. (A) Representative images of fetuses collected at day 41 of pregnancy from a recipient transferred with 25 un-cultured blastocysts (control). (B) Representative images of fetuses collected at day 38 of pregnancy from a recipient transferred with 25 blastocysts derived from morulae stored for $72 \mathrm{~h}$ in NCSU-BSA medium at $37^{\circ} \mathrm{C}$. Scale bar is $1 \mathrm{~cm}$. 


\section{Tables}

Table 1. Outer diameters and zona pellucida (ZP) thicknesses of in vivo-derived morulae stored for $48 \mathrm{~h}$ at different temperatures and in different media.

\begin{tabular}{|c|c|c|c|c|c|c|c|}
\hline \multirow[b]{3}{*}{$\begin{array}{l}\text { Temperature } \\
\left({ }^{\circ} \mathrm{C}\right)\end{array}$} & \multirow[b]{3}{*}{ Medium } & \multicolumn{6}{|c|}{ Time of storage } \\
\hline & & \multicolumn{3}{|c|}{$0 \mathrm{~h}$} & \multicolumn{3}{|c|}{$48 \mathrm{~h}$} \\
\hline & & No. & $\begin{array}{c}\text { Outer } \\
\text { diameter } \\
(\mu \mathrm{m})\end{array}$ & $\begin{array}{c}\text { ZP } \\
\text { thickness } \\
(\mu \mathrm{m})\end{array}$ & No. & $\begin{array}{c}\text { Outer } \\
\text { diameter } \\
(\mu \mathrm{m})\end{array}$ & $\begin{array}{c}\text { ZP } \\
\text { thickness } \\
(\mu \mathrm{m})\end{array}$ \\
\hline 38.5 & Control & 44 & $151.2 \pm 0.7$ & $14.5 \pm 0.3$ & 31 & $238.0 \pm 7.2^{\mathrm{aA}}$ & $4.8 \pm 0.4^{\mathrm{aA}}$ \\
\hline \multirow[t]{2}{*}{25} & TL-PVA & 53 & $152.8 \pm 0.5$ & $14.0 \pm 0.2$ & 39 & $154.7 \pm 0.9^{b}$ & $14.0 \pm 0.3^{b}$ \\
\hline & NCSU-BSA & 60 & $153.2 \pm 0.6$ & $14.8 \pm 0.3$ & 56 & $154.9 \pm 0.9^{b}$ & $14.3 \pm 0.2^{b}$ \\
\hline \multirow[t]{2}{*}{37} & TL-PVA & 55 & $152.5 \pm 0.6$ & $13.5 \pm 0.2$ & 50 & $178.4 \pm 2.0^{\mathrm{cA}}$ & $8.4 \pm 0.3^{\mathrm{cA}}$ \\
\hline & NCSU-BSA & 60 & $151.9 \pm 0.5$ & $14.3 \pm 0.3$ & 59 & $196.1 \pm 2.4^{\mathrm{cA}}$ & $7.8 \pm 0.3^{\mathrm{cA}}$ \\
\hline \multirow{2}{*}{\multicolumn{8}{|c|}{$\begin{array}{l}\text { Controls included morulae cultured under conventional conditions (NCSU-23 medium } \\
\text { supplemented with } 0.4 \% \text { BSA and } 10 \% \text { FCS at } 38.5^{\circ} \mathrm{C} \text { in humidified air with } 5 \% \mathrm{CO} 2 \text { ) for } 48 \mathrm{~h} \text {. } \\
\text { a,b,c Different superscripts in the same column represent significant differences }(\mathrm{P}<0.002) \text {. A }\end{array}$}} \\
\hline & & & & & & & \\
\hline \multicolumn{8}{|c|}{ Capital letter superscript indicates significant differences $(\mathrm{P}<0.001)$ compared with the same } \\
\hline
\end{tabular}




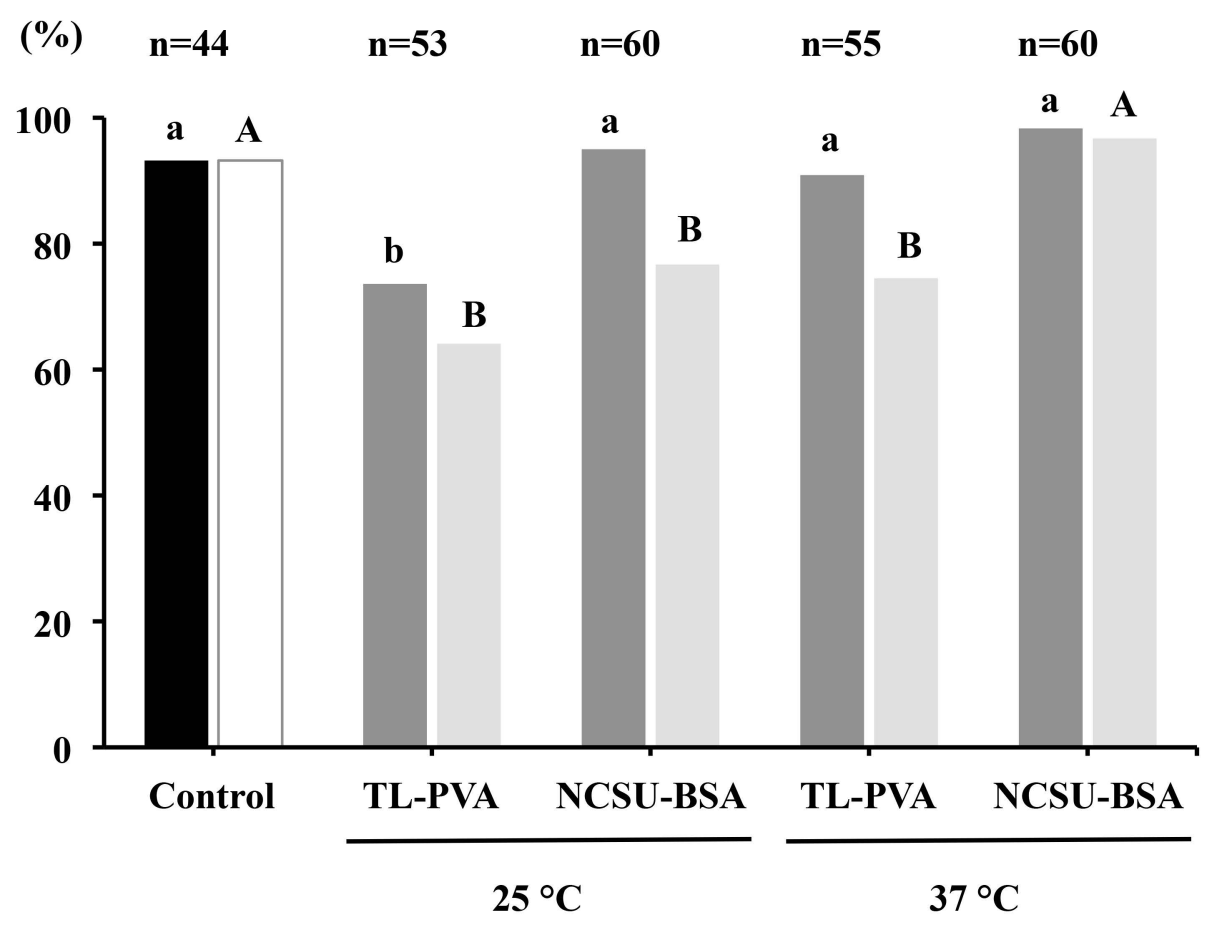


A

Embryonic developmental stage

Storage

Temperature

$\left({ }^{\circ} \mathrm{C}\right)$

\begin{tabular}{ccccc}
\hline 38.5 & Control $^{\#}$ & $4.2 \pm 0.1^{\mathrm{a}}$ & $4.7 \pm 0.1^{\mathrm{a}}$ & $4.8 \pm 0.1^{\mathrm{a}}$ \\
& TL-PVA & $1.4 \pm 0.1^{\mathrm{b}}$ & $3.3 \pm 0.1^{\mathrm{b}}$ & $3.7 \pm 0.1^{\mathrm{b}}$ \\
37 & NCSU-BSA & $1.4 \pm 0.1^{\mathrm{b}}$ & $3.2 \pm 0.1^{\mathrm{b}}$ & $4.2 \pm 0.1^{\mathrm{c}}$ \\
& TL-PVA & $3.4 \pm 0.1^{\mathrm{c}}$ & $3.8 \pm 0.1^{\mathrm{c}}$ & $4.2 \pm 0.1^{\mathrm{c}}$ \\
& NCSU-BSA & $3.5 \pm 0.1^{\mathrm{c}}$ & $4.6 \pm 0.1^{\mathrm{a}}$ & $4.8 \pm 0.1^{\mathrm{a}}$ \\
\hline
\end{tabular}

$\mathrm{B}$

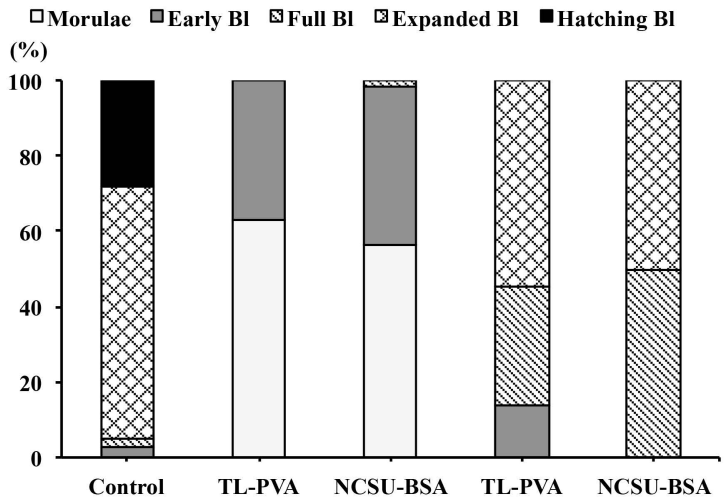

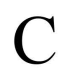

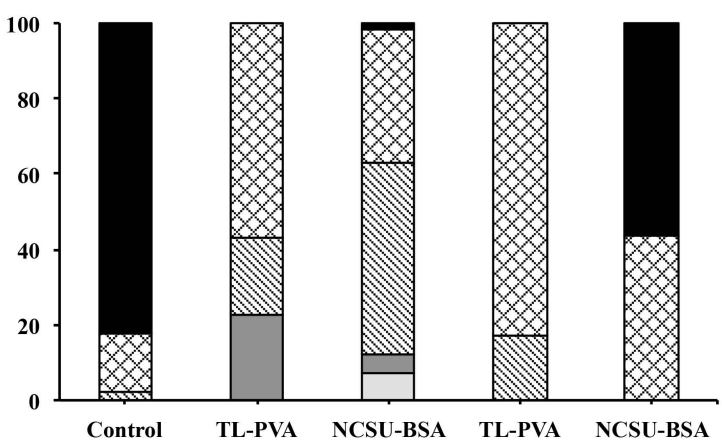

$\mathrm{D}$

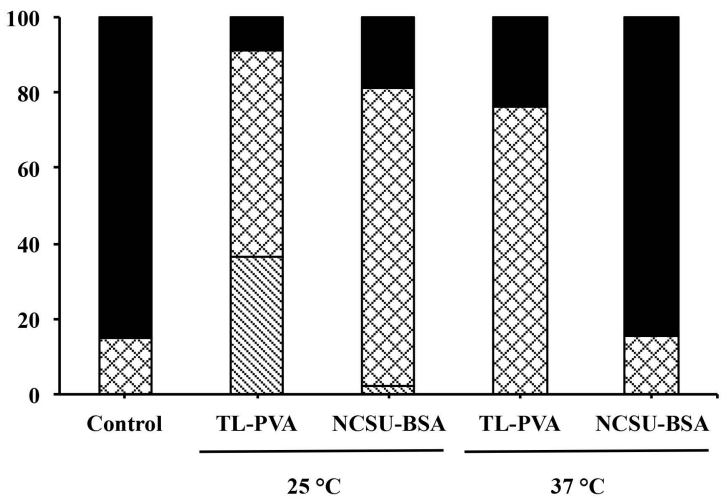

E

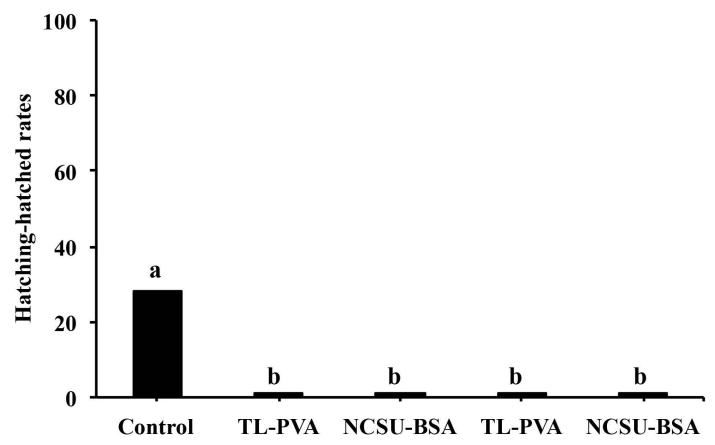

F

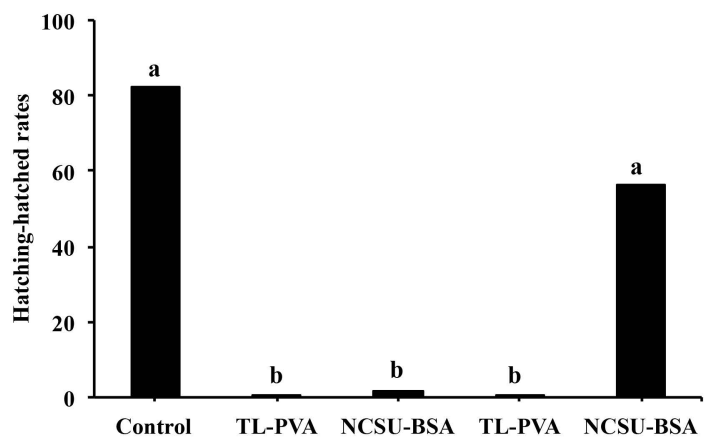

G

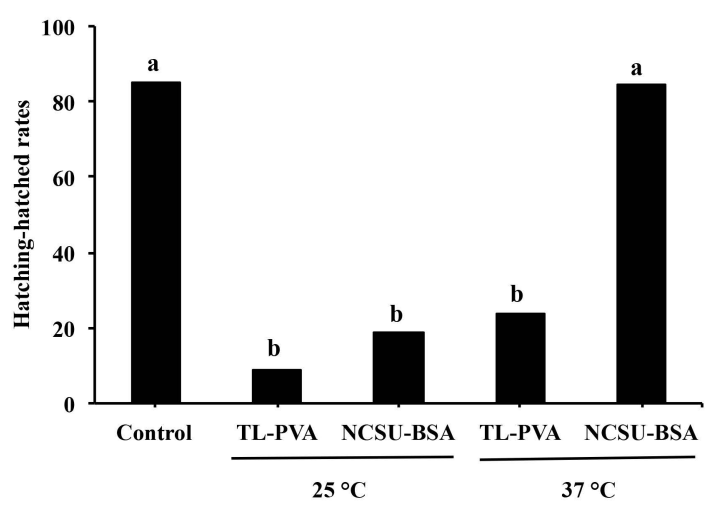


$(\%) \quad n=50$

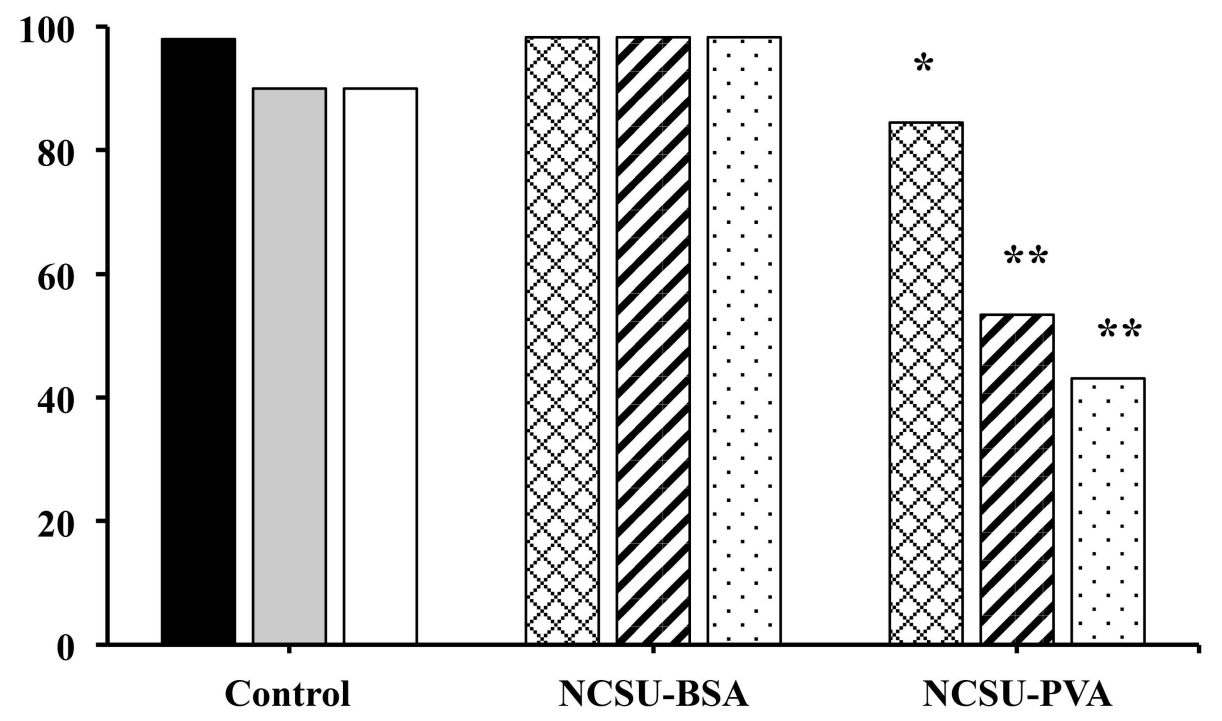


A

\begin{tabular}{|c|c|c|c|}
\hline \multirow[b]{3}{*}{ Medium } & \multicolumn{3}{|c|}{ Embryonic developmental stage } \\
\hline & \multicolumn{2}{|c|}{ Storage } & \multirow{2}{*}{$\frac{\text { Conventional culture* }}{24 \mathrm{~h}}$} \\
\hline & $48 \mathrm{~h}$ & $72 \mathrm{~h}$ & \\
\hline Control $^{\#}$ & $4.1 \pm 0.1^{\mathrm{a}}$ & $4.6 \pm 0.1^{\mathrm{d}}$ & $4.9 \pm 0.1^{\mathrm{a}}$ \\
\hline NCSU-BSA & $3.5 \pm 0.1^{\mathrm{b}}$ & $4.1 \pm 0.1^{\mathrm{e}}$ & $4.8 \pm 0.1^{\mathrm{a}}$ \\
\hline NCSU-PVA & $3.1 \pm 0.1^{\mathrm{c}}$ & $3.6 \pm 0.1^{\mathrm{f}}$ & $4.0 \pm 0.0^{\mathrm{b}}$ \\
\hline
\end{tabular}

B
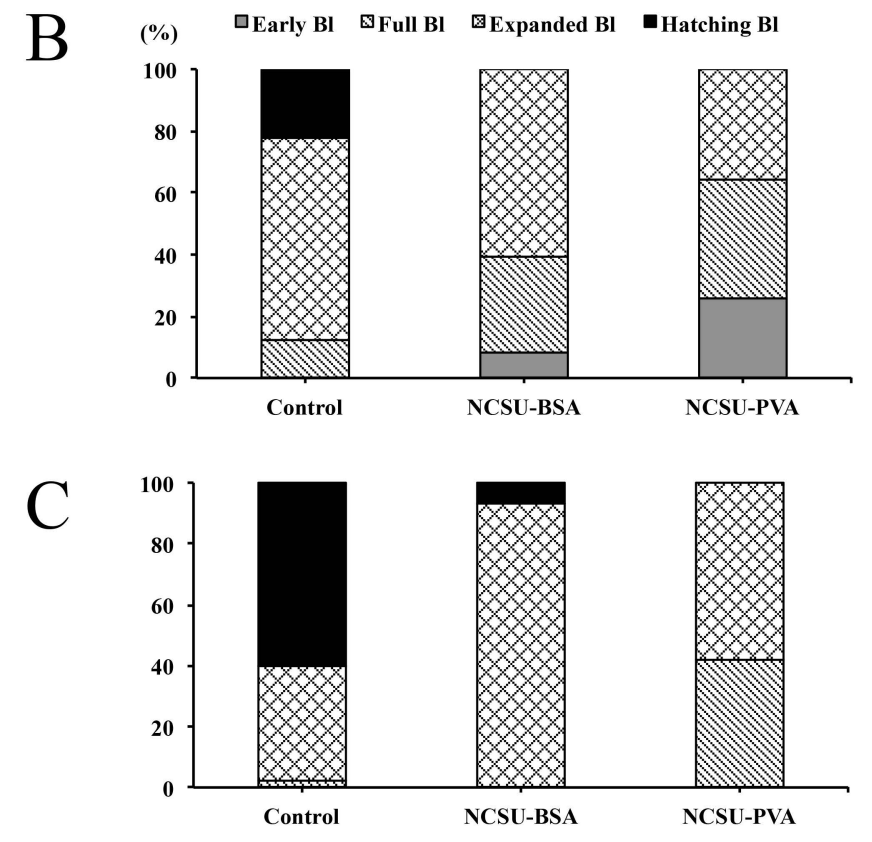

D

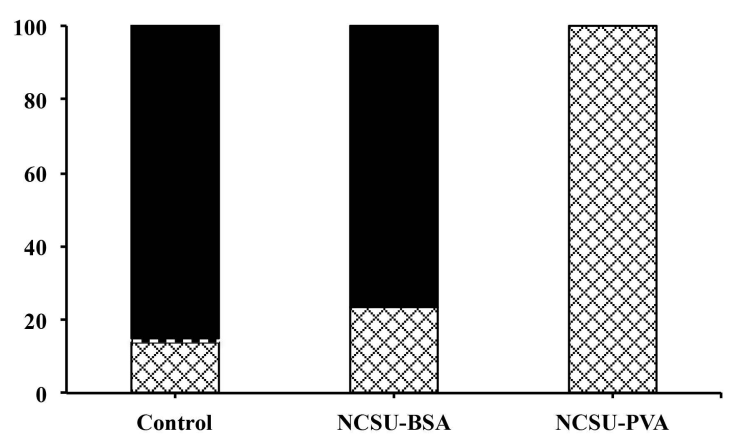

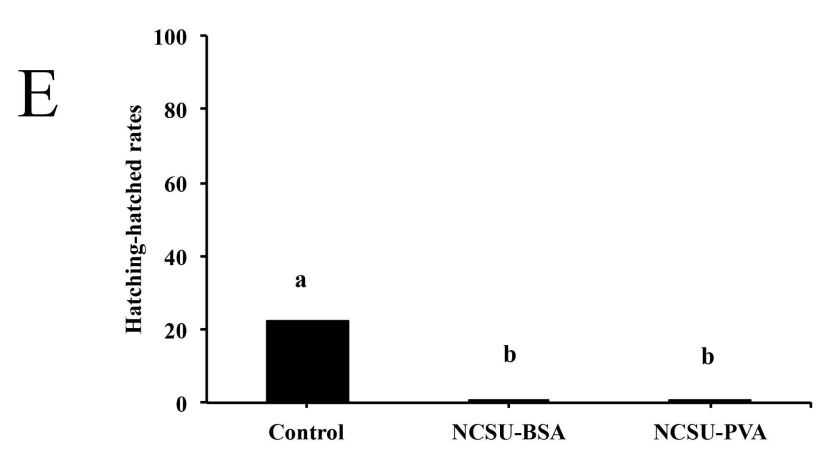
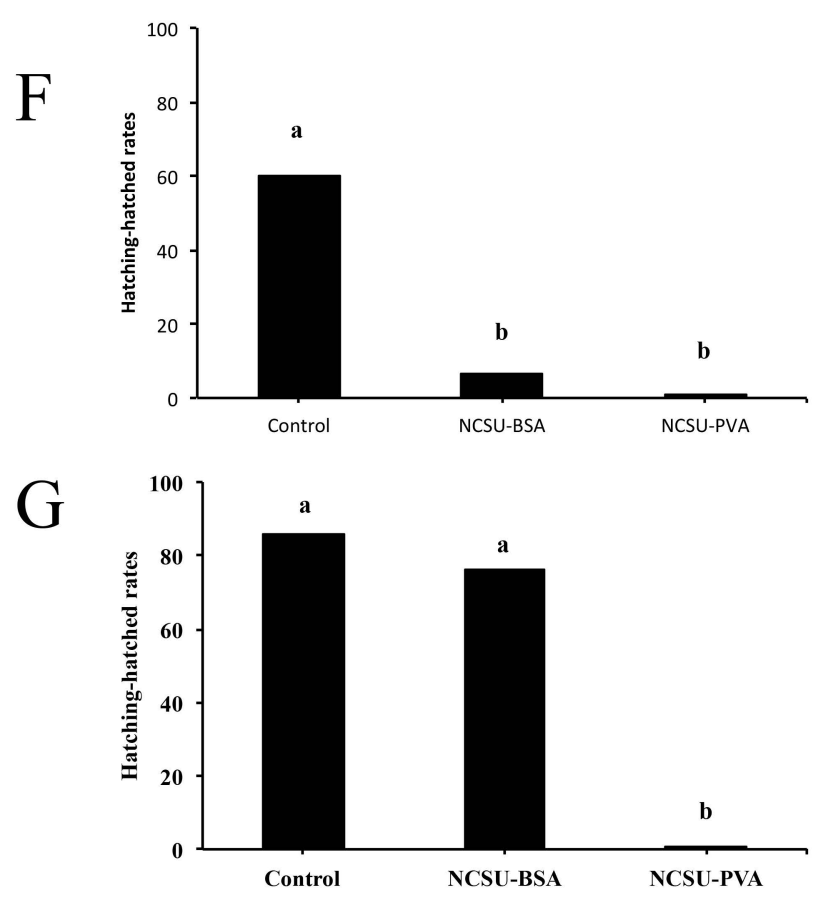


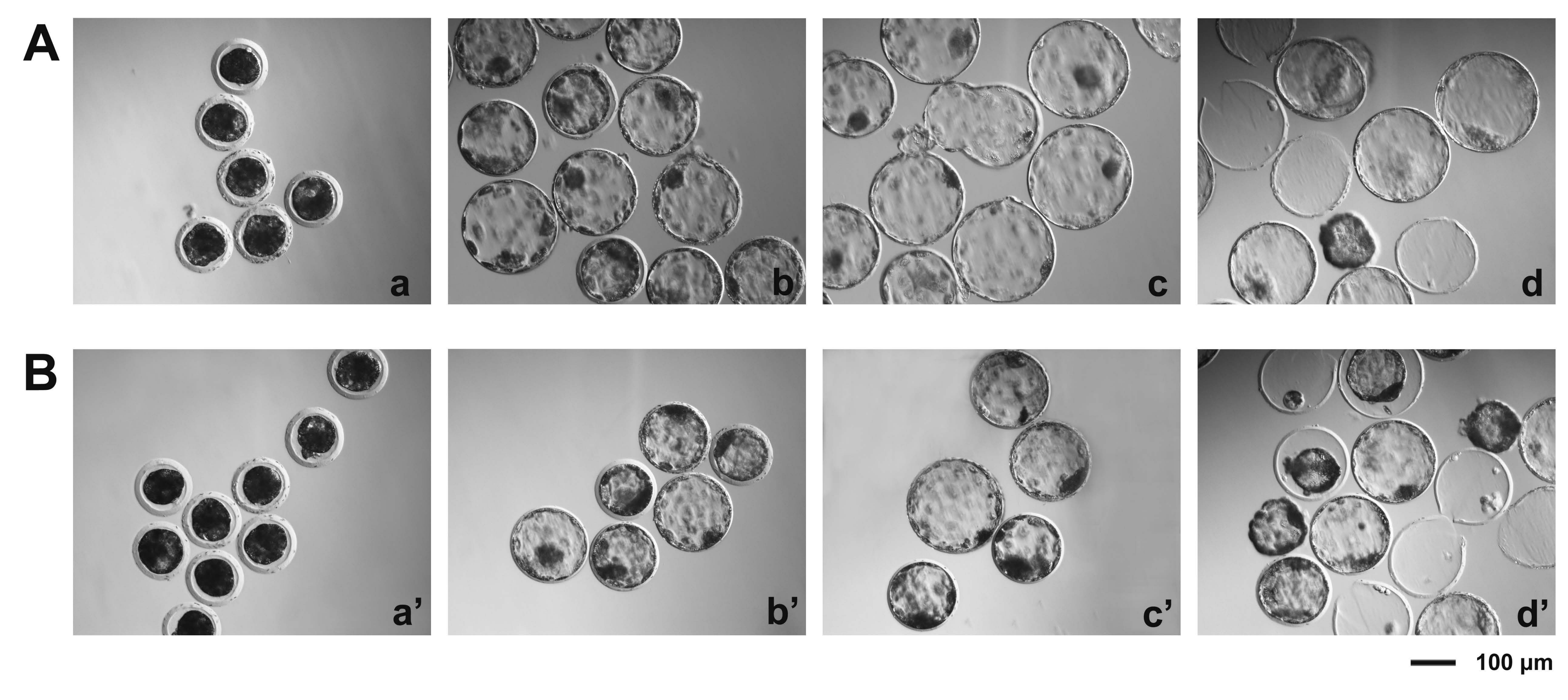


